\title{
Hyponatremia and Bone Fractures: An Intriguing and Often Overlooked Association
}

\author{
Giuseppe Lippi $^{\mathrm{a}}$ Gianfranco Cervellin $^{\mathrm{b}}$ \\ a Section of Clinical Biochemistry, University Hospital of Verona, Verona, and bemergency Department, \\ University Hospital of Parma, Parma, Italy
}

Hyponatremia, conventionally defined as a sodium concentration below the normal reference range, is quite a common condition in the general population and especially in hospitalized patients. Although the concept of "hyponatremia" is seemingly straightforward for many clinicians, some challenges remain regarding the diagnostic thresholds, the distinction between real and pseudohyponatremia, and its relation to human pathologies, including bone fractures.

As regards the first and foremost aspect, i.e., the threshold for diagnosing hyponatremia, different cutoffs have been proposed over the past decades, usually ranging from 135 to $138 \mathrm{mmol} / \mathrm{L}$, while a more generalized consensus apparently exists regarding the definition of severe hyponatremia, which is reflected by a serum or plasma sodium concentration $<125 \mathrm{mmol} / \mathrm{L}$ [1]. No real differences in terms of clinical outcomes have been described for thresholds between 135 and $136 \mathrm{mmol} / \mathrm{L}$, while 137 and $138 \mathrm{mmol} / \mathrm{L}$ seem to be excessively high values. Another essential aspect in diagnosing this condition consists of distinguishing between real and spurious hyponatremia; the latter condition is frequently encountered in patients with hyperproteinemia or hyperlipidemia and it is mainly attributable to a relative decrease in sodium concentration for displacement of water by nonaqueous

\begin{tabular}{ll}
\hline KARGER & $\begin{array}{l}\text { ( ) } 2017 \text { The Author(s) } \\
\text { Published by S. Karger AG, Basel }\end{array}$ \\
$\begin{array}{l}\text { E-Mail karger@karger.com } \\
\text { www.karger.com/mpp }\end{array}$ & $\begin{array}{l}\text { This is an Open Access article licensed under the Creative Commons } \\
\text { Attribution-NonCommercial-4.0 International License (CC BY-NC) } \\
\text { (http://www.karger.com/Services/OpenAccessLicense), applicable to } \\
\text { the online version of the article only. Usage and distribution for com- } \\
\text { mercial purposes requires written permission. }\end{array}$
\end{tabular}
mercial purposes requires written permission.
me online version of the article only. Usage and components in serum or plasma (i.e., the so-called "volume exclusion effect") [2]. This condition is often observed using indirect ion-selective electrodes and must therefore be thoughtfully ruled out before making a definitive diagnosis of hyponatremia.

The final important aspect, which is also the main focus of an article published in this issue of Medical Principles and Practice, is the relation between hyponatremia and bone disorders [3]. In their interesting investigation, Aicale et al. [3] studied over 300 elderly patients admitted during a 2-year period to the local hospital for hip fractures [3]. A diagnosis of hyponatremia was made in 19\% of the patients, which represents an extraordinarily high prevalence compared to that in the general population (i.e., 2\%) [4]. This evidence persuaded the authors to suggest that the sodium concentration should be regularly measured in elderly patients in order to prevent hyponatremia or diagnose it early [3].

This conclusion is obviously straightforward and agreeable, but there were additional aspects that strongly emerged from the findings of this study. The first and foremost was indeed the epidemiologic and possibly biochemical association between hyponatremia and bone fractures. In 2 previous studies it was clearly shown that, indeed, the link between hyponatremia and bone frac-

Prof. Giuseppe Lippi

Section of Clinical Biochemistry, University Hospital of Verona Piazzale L.A. Scuro

IT-37100 Verona (Italy)

E-Mail giuseppe.lippi@univr.it 
tures may not be casual. We [5] previously carried out an epidemiological investigation that included 543 patients with femoral neck fractures [5] and observed a virtually identical prevalence of hyponatremia in $19.5 \%$ of the patient sample. We also estimated that the risk of femoral neck fractures in patients with hyponatremia was nearly twice that in an age- and sex-matched general population. In an ensuing investigation, Cumming et al. [6] studied 127 patients with fragility fractures and showed that the prevalence of hyponatremia on admission was $13.4 \%$, while an additional $12.6 \%$ of the patients developed this condition during hospitalization. Interestingly, a multifactorial etiology was common, whereas thiazide diuretics were the most frequent causes of hyponatremia, followed by dehydration and therapy with proton pump inhibitors. A syndrome of inappropriate antidiuretic hormone secretion could only be diagnosed in a minority of the cases (i.e., 27\%). Besides bone fractures, there is also tangible evidence that the risk of death is $2-3$ times higher in patients with hyponatremia than in those with a normal sodium concentration $[4,7]$.

Regarding the potential physiopathological association, a recent study showed that hyponatremia was strongly associated with vitamin D deficiency [8]. The lat- ter condition is now commonplace in many countries worldwide [9], and thus a clear interplay has been demonstrated between vitamin D metabolism and the physiology of plasma electrolytes, including sodium [10]. Therefore, a direct or indirect link (i.e., mediated by common causal factors of both hyponatremia and vitamin D deficiency) appears plausible between plasma sodium and endogenous synthesis of vitamin $\mathrm{D}$. This hypothesis was recently confirmed by Kruse et al. [11], who showed that both bone mineral content and density are significantly associated with serum sodium and thus hyponatremic patients might have a nearly 2 -fold higher risk of osteoporosis.

In conclusion, although we would all agree that plasma or serum sodium measurement is advisable in elderly patients in order to diagnose hyponatremia, current evidence suggests that this recommendation needs to be reinforced. Sodium testing may be broadened beyond the borders of electrolyte disorders to stratify the risk of (and potentially prevent) bone fractures in high-risk subjects, especially in those with frailty or immobilization or in the elderly. Beside these considerations, it is worth mentioning that a definite therapeutic goal for managing the often occasional finding of mild hyponatremia remains elusive.

\section{References}

1 Cervellin G, Lippi G: How we define hyponatraemia? Eur J Clin Invest 2015;45:1219.

2 Lippi G, Aloe R: Hyponatremia and pseudohyponatremia: first, do no harm. Am J Med 2010;123:e17.

3 Aicale R, Tarantino D, Maffulli N: Prevalence of hyponatremia in patients with elderly hip fracture: a two-year study. Med Princ Pract DOI: $10.1159 / 000480294$.

4 Mohan S, Gu S, Parikh A, et al: Prevalence of hyponatremia and association with mortality: results from NHANES. Am J Med 2013;126: $1127-1137$.
5 Cervellin G, Mitaritonno M, Pedrazzoni M, et al: Prevalence of hyponatremia in femur neck fractures: a one-year survey in an urban emergency department. Adv Orthop 2014;2014: 397059.

6 Cumming K, Hoyle GE, Hutchison JD, et al: Prevalence, incidence and etiology of hyponatremia in elderly patients with fragility fractures. PLoS One 2014;9:e88272.

7 Miller AJ, Theou O, McMillan M, et al: Dysnatremia in relation to frailty and age in community-dwelling adults in the National Health and Nutrition Examination Survey. J Gerontol A Biol Sci Med Sci 2017;72:376-381.

8 Cervellin G, Salvagno G, Bonfanti L, et al: Association of hyponatremia and hypovitaminosis D in ambulatory adults. J Med Biochem 2015;34:450-454.
9 Lippi G, Mattiuzzi C, Aloe R: The impact of seasonality and other determinants on vitamin $\mathrm{D}$ concentration in childhood and adulthood: still an unresolved issue. Ann Transl Med 2016;4:21.

10 Vaidya A, Forman JP: Vitamin D and hypertension: current evidence and future directions. Hypertension 2010;56:774-779.

11 Kruse C, Eiken P, Vestergaard P: Hyponatremia and osteoporosis: insights from the Danish National Patient Registry. Osteoporos Int 2015;26:1005-1016. 